\title{
Development and Evaluation of Low Polycyclic Aromatic Hydrocarbons (PAHs) Improved Fish Smoking Kiln
}

\author{
*JIMAH, A OGIEDU, T. A. \\ Department of Food Technology, Auchi Polytechnic Auchi
}

\begin{abstract}
Polycyclic aromatic hydrocarbons (PAHs) are carcinogenic pollutants which get into foods during smoking. This research was used to develop an improved smoking kiln and to determine its effects of the methods of smoking in reducing the level of PAHs of a locally consumed fish in Nigeria. The fish specie clarias gariepenus (catfish) was smoked with different methods. They are the firewood in open-fire fish smoking drum (FOSD), charcoal using improved fish smoking kiln (CISK) and gas using improved fish smoking kiln (GISK). The PAHs was determined using the Gas Chromatography (GC) coupled with flame ionization detector (FID). Comparison of the concentration of PAHs in smoked fish samples were investigated with the aim of determining the process that has reduced the concentration of the PAHs in the fish samples. The total values of PAHs have shown that the methods FOSD, CISK and GISK have PAHs level of $80.01 \mu \mathrm{g} / \mathrm{g}, 20.95 \mu \mathrm{g} / \mathrm{g}$ and $14.69 \mu \mathrm{g} / \mathrm{g}$ respectively. Benzo(a)pyrene, which is highly carcinogenic and posses health risk was found only in FOSD to be $9.20 \mu \mathrm{g} / \mathrm{g}$, while it was not detected in CISK and GISK respectively. As for other PAHs, they were all detected in FOSD, while fluoranthene was exceptionally high in all the methods used as $22.08 \mu \mathrm{g} / \mathrm{g}, 10.23 \mu \mathrm{g} / \mathrm{g}$ and $5.04 \mu \mathrm{g} / \mathrm{g}$ respectively. However, naphthalene, phenanthrene, anthracene, pyrene, chrysene, benzo(b)fluoranthrene, benzo(k)fluoranthrene, benzo(a)pyrene and benzo(g,h)perylene were not detected (ND) in the developed improved fish smoking kiln. The developed improved fish smoking kiln has been able to reduce the level of PAHs considerably and is therefore recommended.
\end{abstract}

Keywords: Polycyclic aromatic hydrocarbons, Benzo(a)pyrene, smoking kiln, smoked fish, Gas Chromatography DOI: $10.7176 / J N S R / 12-12-04$

Publication date:June $30^{\text {th }} 2021$

\section{INTRODUCTION}

Polycyclic aromatic hydrocarbons (PAHs) constitute a large class of organic compounds that are composed of two or more fused aromatic rings. They are a class of ubiquitous environmental pollutants which can be generated during the preparation of food (Agerstad and Skog, 2005). They are primarily formed by incomplete combustion or pyrolysis of organic matter and during various industrial processes (Silva et al, 2011). PAHs generally occur in complex mixtures which may consist of hundreds of compounds. Humans are exposed to PAHs by various pathways. While for non-smokers the major route of exposure is consumption of food, for smokers the contribution from smoking may be significant (Agerstad and Skog, 2005). Food can be contaminated from environmental sources, industrial food processing and from certain home cooking practices (EFSA, 2008). On the other hand, PAHs are also found in foods as a result of certain industrial food processing methods such as smoke curing, broiling, roasting and grilling over open fires or charcoal which permits the direct contact between food and combustion products (Silva et al., 2011). In general, PAHs are not present individually but in mixtures. Sixteen PAHs that have been extensively monitored are the compounds included in the United States Environmental Protection Agency (USEPA) list of priority organic pollutants (USEPA, 1994). Of these 16 PAHs, Benzo(a)pyrene $(\mathrm{BaP})$ is probably the most studied and has been described by the International Agency for Research on Cancer (IARC) as probable human carcinogen in 1987 (IARC, 1987). Thus, the determination of BaP has been widely used in environmental analysis as marker for the entire PAH content (Otahen, 2021).

Across Africa various traditional methods are employed to process, preserve and store fish. These include smoking, drying, salting, frying and fermenting and various combinations of these treatments (SFMP, 2016). Smoking is a traditional processing technique used to preserve fish. It also gives colour and a range of tastes appreciated by consumers. It consists of exposing fish to the effects of heat and smoke, both produced by the combustion of biomass (wood, sawdust, coconut husks, etc) (Kamaldeen et al, 2016). The advantages of smoking fish are manifold: it prolongs shelf life, enhances flavour, reduces waste in times of bumper catches and permits storage for the lean season. It increases protein availability to people throughout the year and makes fish easier to pack, transport and market. It is a major source of income for coastal-dwelling communities and traders. In Nigeria, smoking is the most widely-used method for preserving fish and is the most common activity for women in fishing communities. Out of the total of 194,000 metric tons of dry fish produced in Nigeria, about $61 \%$ of it was smoked (Silva et al, 2011). It has been estimated that between 70 and 80 percent of the domestic marine and freshwater fish catch is consumed in smoked form (SFMP, 2016). Catfish (Clarias gariepinus) has been reported to be a very important freshwater fish in Nigeria. It has enjoyed wide acceptability in most parts of the country because of its unique taste, flavour and good texture. It is widely distributed, extensively cultivated in ponds. (Kamaldeen et al, 
2016). The actual levels of PAHs in smoked foods depend on several variables in the smoking process, including type of smoke generator, combustion temperature, and degree of smoking (Silva et al, 2011). The composition of the smoke and the conditions of processing affect the sensory quality, shelf life, and wholesomeness of the product. Potential health hazards associated with smoked foods may be caused by carcinogenic components of wood smoke; mainly PAHs, derivatives of PAHs, such as nitro-PAH or oxygenated PAH and to a lesser extent heterocyclic amines (Silva et al, 2011). The smoke for smoking of food develops due to the partial burning of wood, predominantly hardwood, softwood and bagasse (Rey et al., 2009 and Silva et al, 2011).

In Nigeria, kiln smoking ranges from traditional open fire to the mud brick, cylindrical drum, and brick. Recent studies have shown that fish smokers produce products with levels of Polycyclic Aromatic Hydrocarbons (PAH) that are well above current recommended levels for human health (Kamaldeen et al, 2016). Most of the smoking kilns available were unable to tackle the critical challenges faced by the end-users. In addressing the problems faced in traditional smoking process, mechanical smoking kiln was developed by NSPRI (2012). Some of limitations of the smoking kiln developed by NSPRI (2012) and the traditional stoves are:

- $\quad$ poor control of the fire power resulting in high temperatures well above optimum

- the smoking of fish using traditional kilns is generally carried out with wood at temperatures of $300^{\circ} \mathrm{C}$ to $700^{\circ} \mathrm{C}$

- in many cases cooking and smoking phases are concurrent

- $\quad$ in those models, nothing preventing oil from dropping on the fire

- $\quad$ effect of not collecting the falling oil drops and providing a roasting surface heated by the fire and the PAH rises into the fish above (Kamaldeen et al, 2016).

- $\quad$ Effects of not using clean energy other than the firewood.

This has provoked us to develop an Improved smoking kiln which cannot only significantly reduced fuel wood consumption and reduce human exposure to heat and smoke but also to reduce the PAHs content of the smoked fish. Based on this, a new and improved smoking kiln is fabricated with improved fish drying technologies and with adequately efficient fuel device that produces dried fish with low PAH levels. The constructed smoking kiln was also evaluated.

\section{MATERIALS AND METHODS}

\section{Collection of Materials}

The clarias gariepenus (catfish) was purchased from Uchi market, Auchi, Edo state of Nigeria. The firewood used in the generation of heat and smoke were sourced from a local seller while the traditional Open-fire drum for the smoking was at the Department of Food Technology, Auchi Polytechnic Auchi. The new improved smoking kiln used for this research was constructed by the researcher, from the department of Food Technology, Auchi Polytechnic Auchi. The materials used for the construction of the new improved smoking kiln, mainly galvanized and stainless steel were purchased from a dealer in Auchi and the gas cylinder was also purchased in local store.

\section{Components of the developed fish smoking kiln}

The developed smoking kiln comprises of various components with their specific function include the following:

- Smoke cabinet is the chamber where fish are kept for smoking and drying

- Fish trays is made of wire mesh where the fish are placed for smoking and drying in the chamber

- Oil collectors is for collecting oil dripping from the fish to prevent it into flame

- Charcoal pot is design to contain charcoal for heating

- Gas burner is used to generate heat into the kiln chamber

- Chimney is used to conduct the smoke/heat coming from the chamber into the surrounding

- Thermometer is used to know the temperature in the heated chamber

- Rolling tyres is used to move the kiln to any location

- Fibre glass which is embedded is used to prevent heat loss in the heated chamber

- Silver paint spray was used the beautify the exterior part of the kiln

Figure 1 shows some of the component parts of the developed improved fish smoking kiln

\section{Design Consideration}

In order to reduce PAHs levels in smoked fish to a level nearer to European Union (EU) standard, the following are considered in the improved kiln design:

- The smoking of fish can be carried out with wood, charcoal or gas

- There is good control fire power resulting at controlled temperatures.

- There advantage of using a very clean combustion with low PAHs

- In case of fire wood, cooking and smoking phases should be done separately: the separation of the two phases presents the advantage of cooking first without or with very low levels of PAHs, then smoking 
during a reduced duration.

- In this model, there is oil collectors preventing oil from dropping on the fire which could have generated PAHs rising into the fish kept above.

\section{Smoking of fish}

Clean water was used to wash the fish before gutting and they were washed again and drained. The fish were spread in trays and taken for smoking. The firewood was used in this case of traditional open-fire drum. The smoking was done for about 7-8hours. As for the new developed improved smoking kiln, the charcoal and gas were used as the source of heat. The kiln was opened for fish to be loaded in the trays and gently closed again for the drying process. The gas/charcoal was ignited to provide fire for heating at the burner section. The kiln temperature was regulated between 80 and $100^{\circ} \mathrm{C}$ and the fish were dried for about 10 to 12 hours. After the drying processes, the smoked and dried fish were cooled and packaged and samples were taken to the laboratory for PAHs analysis.

\section{Analysis of PAHs}

Extraction: The samples were each pulverized using a manual grinding machine to ensure homogenization. Five grams $(5 \mathrm{~g})$ of the pulverized sample was thoroughly mixed with $10 \mathrm{~g}$ of anhydrous sodium sulphate in a mortar (Amos-Tautua et al, 2013) to absorb moisture. The homogenate was placed into an extraction thimble and covered with a Whatman filter paper (125 mm diameter).This was then inserted into a Soxhlet extraction chamber of the Soxhlet extraction unit. Extractions were then carried out with $50 \mathrm{~mL}$ mixture of redistilled n-hexane and dichloromethane in the ratio 3:1 for effective recovery. Subsequently, the crude extract was filtered through a layer of anhydrous sodium sulphate. The obtained filtrate was evaporated to near dryness.

Clean up: The clean-up of the extract was carried out using activated silica gel and anhydrous $\mathrm{Na}_{2} \mathrm{SO}$. The silica gel column was prepared by loading an activated silica gel $(12 \mathrm{~g})$ onto a chromatographic column (id= $1 \mathrm{~cm})$. About $1 \mathrm{~g}$ of anhydrous $\mathrm{Na}_{2} \mathrm{SO}_{4}$ was added to the top of the silica gel in the column. After conditioning the columns with $20 \mathrm{~mL}$ hexane the sample was applied and eluted with $200 \mathrm{ml}$ of mixture of Dichloromethane : Hexane (3:1). The eluate was collected into an evaporating flask and rotary evaporated to near dryness. The dry eluate was then dissolved in $1 \mathrm{~mL} n$-hexane for Gas Chromatographic analysis (Amos-Tautua et al, 2013).

Instrumental analysis: The polycyclic aromatic hydrocarbon analysis was carried out using gas chromatograph system. The system consisted of a Hewlett Packard Model 5890 gas chromatography (GC) equipped with a flame ionization detector (FID) and a data processor (Hewlett Packard, Wilmington, DE, USA). The column used was HP-1932530, a non-polar, fused-silica capillary column $(30 \mathrm{~m}$ length $\times 25 \mu \mathrm{m}$ inner diameter $\times 0.25 \mu \mathrm{m}$ film thickness). The oven temperature was set initially at $60^{\circ} \mathrm{C}(5 \mathrm{~min}$ hold $)$, increased to $250^{\circ} \mathrm{C}$ at $15^{\circ} \mathrm{C} / \mathrm{min}$. $(14 \mathrm{~min}$ hold), and a final temperature of $320^{\circ} \mathrm{C}$ at $10^{\circ} \mathrm{C} / \mathrm{min}(4 \mathrm{~min}$ hold). Nitrogen gas was used as the carrier gas at a flow rate of $1 \mathrm{~mL} / \mathrm{min}$ at a pressure of $30 \mathrm{psi}$. The injector temperature was set at $250^{\circ} \mathrm{C}$, injection volume was $1 \mathrm{~mL}$ and the detector temperature was set at $320^{\circ} \mathrm{C}$. Verification of peaks was carried out based on retention times compared to those of external PAHs standards (Amos-Tautua et al, 2013). 
RESULTS

Table 1: Concentration of PAHs ( $\mu \mathrm{g} / \mathrm{g}$ ) on smoked clarias gariepenus (catfish) in firewood (FOSD), Charcoal (CISK) and gas (GISK)

\begin{tabular}{|c|c|c|c|}
\hline \multirow[b]{2}{*}{ Parameters } & \multicolumn{2}{|c|}{ Samples } & \multirow[b]{2}{*}{ gas (GISK } \\
\hline & firewood (FOSD) & Charcoal (CISK) & \\
\hline Naphthalene & 1.1344 & ND & ND \\
\hline Acenaphthylene & 4.2963 & 2.0101 & 1.1823 \\
\hline Acenaphthene & 2.1183 & 3.3323 & ND \\
\hline Fluorene & 0.3372 & 0.3174 & 0.1258 \\
\hline Phenanthrene & 1.2923 & ND & ND \\
\hline Anthracene & 1.2094 & ND & ND \\
\hline Fluoranthene & 22.0752 & 10.2330 & 5.0443 \\
\hline Pyrene & 12.3981 & ND & ND \\
\hline Chrysene & 4.4259 & $\mathrm{ND}$ & ND \\
\hline Benzo(a)anthracene & 6.9393 & ND & 5.0662 \\
\hline Benzo(b)fluoranthene & 2.4837 & ND & ND \\
\hline Benzo(k)fluoranthene & 5.9991 & ND & ND \\
\hline Benzo(a)pyrene & 9.2002 & ND & ND \\
\hline Indeno(1,2,3-cd)pyrene & 1.7632 & ND & 2.2025 \\
\hline Dibenzo $(\mathrm{a}, \mathrm{h})$ anthracene & 2.0086 & 6.0581 & 1.0676 \\
\hline Benzo(g,h,i)perylene & 2.3285 & ND & $\mathrm{ND}$ \\
\hline TOTAL PAHs $(\mu \mathrm{g} / \mathrm{g})$ & 80.0095 & 20.9509 & 14.6887 \\
\hline
\end{tabular}

KEY:

FOSD $=$ Firewood in open-fire fish smoking drum

CISK $=$ Charcoal using improved fish smoking kiln

GISK $=$ Gas using improved fish smoking kiln

$\mathrm{ND}=$ Not detected

\section{DISCUSSION}

Various smoking treatments were given to the clarias gariepenus (catfish) as shown in Table 1. The total concentration of the sum PAHs in the Gas using improved fish smoking kiln (GISK) was the least, having a concentration of $14.69 \mu \mathrm{g} / \mathrm{g}$. While that of the Firewood in open-fire fish smoking drum (FOSD) has the highest concentration of PAHs as $80.01 \mu \mathrm{g} / \mathrm{g}$ and showing all the individual concentration of PAHs. Like the GISK, most of the individual PAHs were not also detected in the Charcoal using improved fish smoking kiln (CISK) dried fish samples. This could be as a result of there was no visible smoke generated in these methods which could have generated much PAHs. The level of total PAHs in the FOSD fish sample was higher than those in the CISK and GISK. The PAHs levels were found to vary with the heat source. This agrees with the findings of some researchers who studied the effects of cooking methods on foods (Muthumbi et al., 2003; Rey et al., 2004 and Silva et al, 2011).

Benzo(a)pyrene, which is highly carcinogenic and posses health risk was found to be higher only in FOSD to be $9.20 \mu \mathrm{g} / \mathrm{g}$, while CISK and GISK has no values and were not detected (ND) respectively. As for other PAHs, they were all detected in FOSD, while fluoranthene was exceptionally high in all the methods used as $22.08 \mu \mathrm{g} / \mathrm{g}$, $10.23 \mu \mathrm{g} / \mathrm{g}$ and $5.04 \mu \mathrm{g} / \mathrm{g}$ respectively. However, naphthalene, phenanthrene, anthracene, pyrene, chrysene, benzo(b)fluoranthrene, benzo(k)fluoranthrene, benzo(a)pyrene and benzo(g,h)perylene were not detected (ND) in the fish samples of the developed improved fish smoking kiln. This result showed that Benzo(a)pyrene (BaP), a bio-indicator was not detected in the charcoal and gas improved smoking kiln samples. BaP is the most studied carcinogenic polycyclic aromatic hydrocarbon and one of the most potent and it is often used as a toxicological prototype or surrogate for all carcinogenic polycyclic aromatic hydrocarbons (Collins et al., 1991). The EU has established a maximum permissible level for $\mathrm{BaP}$ of $5 \mu \mathrm{gkg}^{-1}$ weight.

All mentioned authors attribute the highest PAHs generation during grilling or barbecue through pyrolysis during charbroiling of fish products and either deposition and penetration of smoke components into foods and they found a link between fat foods and PAH levels. Biological membranes are mostly composed of lipids (oils); majority of organic pollutants are lipophilic. It has been suggested that the larger the lipid content of the biological membrane, the higher is the rate of uptake of pollutants (Silva et al., 2011). The hypothesis is that melted fat from the heated fish drips onto the hot flame and is pyrolyzed, giving rise to PAHs generation, which are then deposited on the fish surface as the smoke rises. Their findings were consistent with the findings from this study. Interestingly, 
the developed improved smoking kiln has oil collector that does not allow the fat to drip into the flame.

\section{CONCLUSIONS}

Smoking using the traditional Firewood open-fire smoking kiln was found to generally increase the PAHs levels. The results revealed that the fish samples smoked by the developed improved smoking kiln do not constitute a health risk, as benzo(a)pyrene, which is carcinogenic was not detected. Hence, the developed improved fish smoking kiln has been able to reduce the level of PAHs considerably and is therefore recommended.

\section{ACKNOWLEDGEMENT}

The authors are thankful to TETfund for providing this Institution Based Research (IBR) grant to facilitating this research. This indeed has given us the opportunity to contribute our quota to the nation building in term of food production and development. Thank you so much.

\section{DEDICATION}

This work is dedicated to the memory of my Co-researcher, the late Mr Ogiedu, T. A. who had passed on during the period of this research. May his soul rest in peace - Amen

\section{REFERENCES}

Agerstad, M. J. and Skog, K. (2005). Review genotoxicity of heat-processed foods. Mutation Research, 574:156172.

Amos-Tantua, B. M. W., Inengite, A. K., Abasi, C. Y. and Anirize, G.C. (2013). Evaluation of Polycyclic Aromatic Hydrocarbons and some Heavy Metals in Roasted Food Snacks in Amassoma, Niger-Delta, Nigeria. African Journal of Environmental science and Technology 7(10) 961 - 966

Collins, J. F., Brown, J. P, Dawson, S. V.and Marty, M. A. (1991). Risk Assessment for benzo[a]pyrene. Regulatory Toxicology and Pharmacology, 13: 170-184..

EFSA (2008) Polycyclic Aromatic Hydrocarbon in food, European Food Safety Authority EFSA Journal 724, 1114

IARC. (1987). Overall evaluation of carcinogenicity: IARC Monographs on the Evaluation of Carcinogenic Risks to Humans, Suppl. 7, 1-42, International Agency for Research on Cancer, Lyon.

Kamaldeen, O. S., Isiaka, A. A., Arowora, K. A., \& Awagu, E. F. (2016). Development of Improved Fish Smoking Kiln. International Journal of Engineering Science and Computing. (7) 1925 -1932)

Muthumbi W, Boever P, Pieters JG, Siciliano S, DrsquoHooge, W, Verstraete, W. (2003). Polycyclic aromatic hydrocarbons (PAHs) and estrogenic compounds in experimental flue gas streams. Journal of Environmental Quality. 32: 417-422.

Nigerian Stored Products Research Institute (NSPRI) (2012). Development of Fish Smoking Kiln, A Paper Presented at Monthly Seminar Program at NSPRI Kano, Kano State, Nigeria.

Otahen, S. O. (2021). Study of the Level of Polycyclic Aromatic Hydrocarbons in Smoked Fish. A Project Work of Food Technology Department, Auchi Polytechnic Auchii. Unpublished pp 26, 31 - 35

Rey-Salgueiro L, Garcia-Falcon M. S, Soto-Gonzalez B, Simal-Gandara, J. (2004). Procedure to measure the level of polycyclic aromatic hydrocarbons in wood ashes used as fertilizer in agro-forestry soils and their transfer form ashes to water. Journal of Agricultureal Food Chemistry. 52: 3900-3904

SFMP (2016). Low PAHs Improved Fish Smoking Stove Design Development Report. Sustainable Fisheries Management Project, USAID/GHANA. P7 - 8 and 15 - 20

Silva, B. O., Adetunde, O. T., Oluseyi, T. O., Olayinka, K. O. and Alo, B. I. (2011). Effects of Methods of Smoking on the Levels of PAHs in Some Locally Consumed Fishes in Nigeria. African Journal of Food Sciences 5(7): $384-391$

USEPA (1994). (United States Environmental Protection Agency), Appendix A Part 423 http://www.epa.gov/waterscience/methods/pollutants. html. 


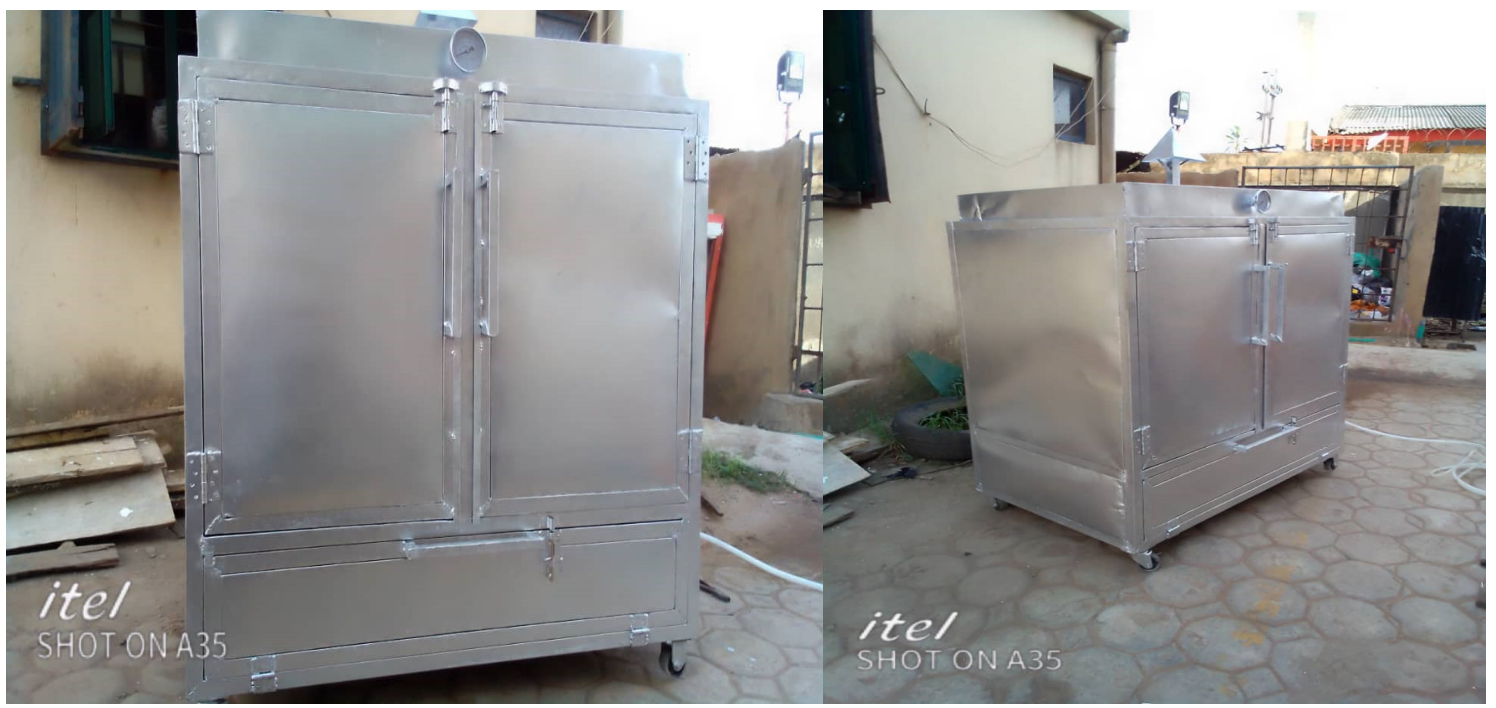

Front view

Side view

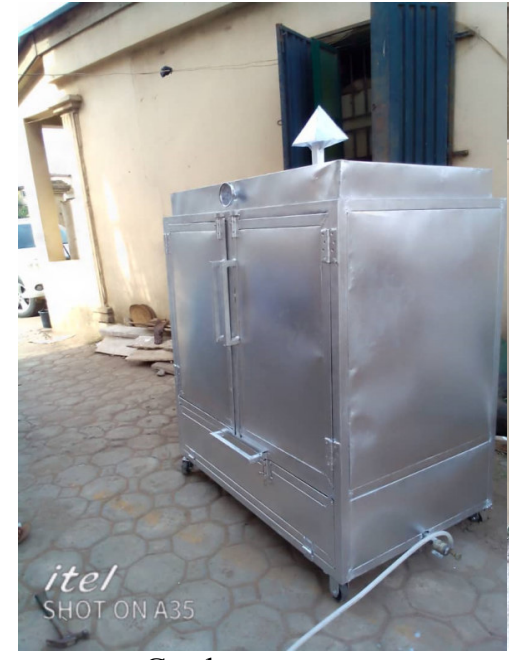

Gas hose

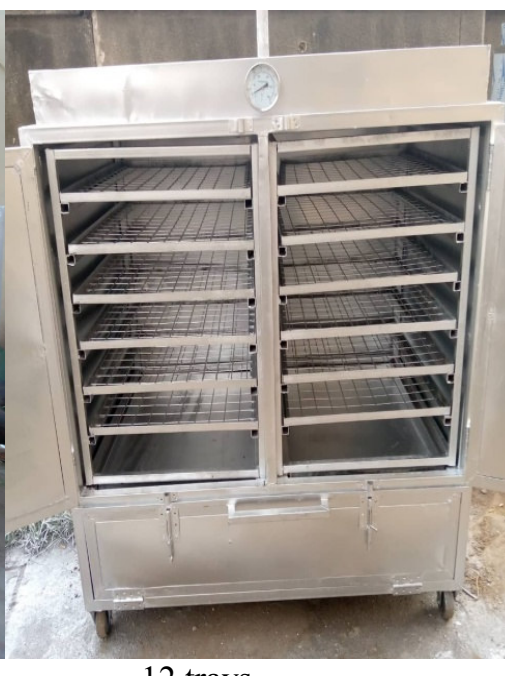

12 trays

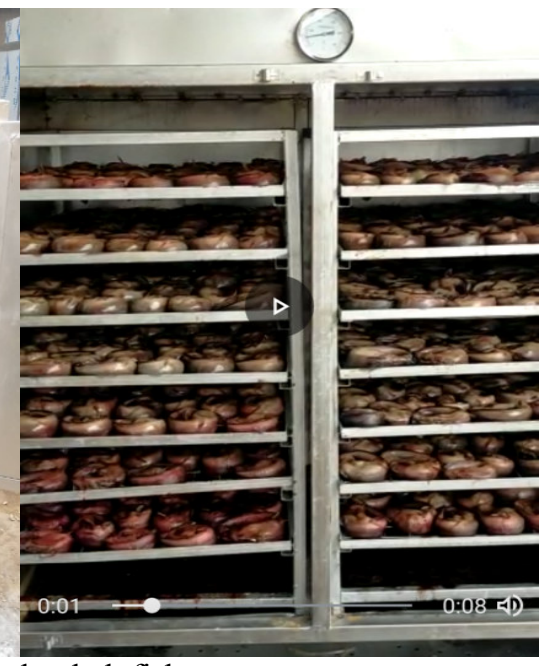

loaded fish

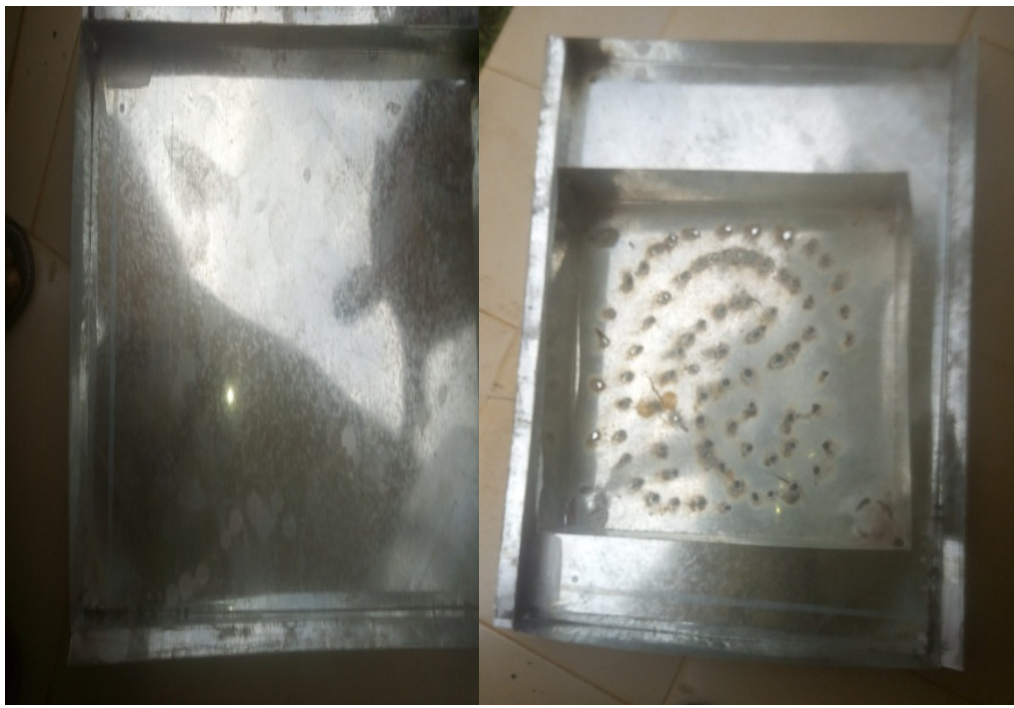

Oil collector
Charcoal Plate

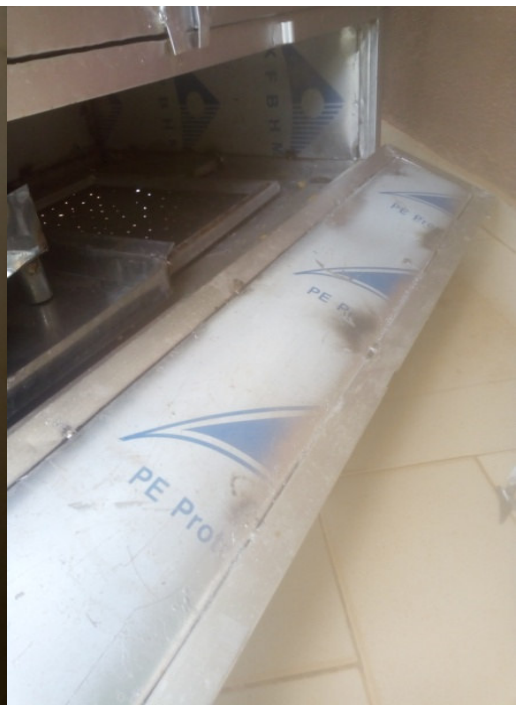

Burner chamber

Figure 1: Some component parts of the developed improved fish smoking kiln 